\title{
Genetic diversity assessment of the Mycobacterium tuberculosis isolates of patients with tuberculosis in Karaj, Iran
}

Morassa Sadat Farnad

Islamic Azad University Shahrekord Branch

Hassan Momtaz ( $\nabla$ hamomtaz@yahoo.com )

Islamic Azad University Shahrekord Branch

Nader Mosavari

Razi Vaccine and Serum Research Institute

Yahya Khosravi

Alborz University of Medical Sciences

Keyvan Tadayon

Razi Vaccine and Serum Research Institute

Research

Keywords: Mycobacterium tuberculosis, Genetic diversity, IS6110-RFLP, Iran

Posted Date: June 30th, 2021

DOl: https://doi.org/10.21203/rs.3.rs-659149/v1

License: (9) This work is licensed under a Creative Commons Attribution 4.0 International License. Read Full License 


\section{Abstract \\ Background}

Tuberculosis (TB) is an old issue that is presently measured as a significant challenge. Molecular characterization of Mycobacterium tuberculosis has contributed to TB control. The present survey was aimed to assess the genetic diversity of $M$. tuberculosis strains isolated from patients with TB in Karaj, Iran.

\section{Methods}

Seventeen M. tuberculosis isolates from 2012 to 2013 were collected and subjected to an IS6110 restriction fragment length polymorphism (IS6110-RFLP) analysis. Demographically, 6 females and 14 males who had Iranian citizenship were included in this study.

\section{Results}

Sixteen different genetic types were obtained after enzymatic digestion and RFL analysis. Copy numbers of IS6110 in each isolate ranged from 0 to 12 . The majority of isolates (66\%) harbored copy numbers between 6 and 12. Each isolates harbored 6.9 copies of the IS6110 marker. Nine isolates harbored 10 to 12 copies of the IS6110 marker, 5 isolates harbored 6 to 10 copies, and 2 others harbored copies less than 6 . No copy of IS6110 was found among the 4 isolates. No relationship was found between gender and copy numbers.

\section{Conclusions}

The high genetic diversity found amongst the M. tuberculosis isolates maybe show different sources of infection and the importance of reemerging of the TB. However, further surveys should perform to assess other molecular epidemiologic aspects of $M$. tuberculosis in Iran.

\section{Background}

Tuberculosis (TB) is a worldwide health threat globally. According to the World Health Organization (WHO) report, there were 10.0 million new TB cases (5.6 million men, 3.2 million women, and 1.2 million children), which resulted in 1.4 million deaths in 2020 [1]. Despite an auspicious decline in the incidence of TB in Iran from 36 cases per 100,000 people in 1990 to 17 cases per 100,000 people in 2010 [2], TB endures being an important public health threat among Iranians [3].

TB is a complicated and polymorphic disease $[4,5]$. Various combination therapy is available to treat TB [6]. However, there is an emergence of multidrug-resistant TB (MDR-TB) [7]. Presently, the MDR-TB has a 
cumulative incidence rate globally. Additionally, MDR-TB is a significant public health threat in TB control and prevention [8]. Thus, it is essential to use rapid and sensitive TB diagnostic methods and assess the new epidemiological aspects of TB in an area with a high incidence rate $[9,10]$.

Genotyping of $M$. tuberculosis strains using IS6110 restriction fragment length polymorphism (IS6110RFLP) is considered a practical approach in TB molecular epidemiology $[11,12]$. Such genotyping helps TB control by allowing the unpredicted outbreaks identification and laboratory cross-contamination, and it helps discriminate exogenous reinfection from endogenous reactivation, in that way permitting an understanding of the strain's genetic diversity [13].

According to the high incidence rate of TB among Iranians and uncertain status of the genotyping patterns of isolates in some area of Iran, the present survey was aimed to assess the molecular features of the M. tuberculosis isolates from the sputum samples of patients referred to the Alborz tuberculosis center using the RFLP method.

\section{Materials And Methods}

\section{Ethical issues}

Written informed consent was taken from volunteer patients or their parents. The relevant authorities issued ethical approval for this retrospective genotyping work at the Alborz University of Medical Sciences Ethics Committee. The present survey principles were ethically approved by the Department of Tuberculin \& Mallein, Razi Vaccine \& Serum Research Institute, Agricultural Research, Education and Extension Organization (AREEO), Karaj, Iran.

\section{Samples and preparation}

Twenty sputum samples were taken from randomly selected 20 pulmonary TB-suspected outpatients. These were visiting patients to the university hospitals of Alborz from December 2012 to October 2013. Patients' demographic data were collected, and their consent through questionnaires filled out at the clinic when specimens were taken. Samples were immediately transferred to Razi Vaccine \& Serum Research Institute, Karaj, Iran, for further analysis. Samples were subjected to Petroff's protocol for digestion/decontamination.

\section{M. tuberculosis culture}

Processed samples were used to inoculate slopes of plain (glycerinated) and Lowenstein-Jensen medium (LJ) supplemented with sodium pyruvate and glycerol (Merck, Germany). Cultures were incubated at $37^{\circ} \mathrm{C}$ for 12 weeks. The weekly inspection was performed to found any bacterial growth. The acid-fast staining was used for the microscopic assessment of cultures with visual features of $M$. tuberculosis complex (MTC) [14]. All principles were performed according to the instructions of the Department of Tuberculin \& Mallein, Razi Vaccine \& Serum Research Institute, Karaj, Iran. Identification of 
M. tuberculosis isolates was performed using the PCR amplification of the 16S rRNA gene and IS6110 marker $[15,16]$.

\section{DNA extraction and quality assessment}

For DNA extraction, 3 loopful colonies of $M$. tuberculosis were scraped, transferred to a microtube that contained $400 \mu \mathrm{l}$ Tris-ethylenediaminetetraacetic acid (EDTA) buffer $(\mathrm{pH} 8)$ inactivated by heating using a water bath $\left(80^{\circ} \mathrm{C}\right.$ for $\left.30 \mathrm{~min}\right)$. Then, $50 \mu \mathrm{l}$ of $10 \mathrm{mg} / \mathrm{mL}$ lysozyme was added, vortexed, and incubated overnight $\left(37^{\circ} \mathrm{C}\right)$. Sodium dodecyl sulfate (SDS)/proteinase K $(70 \mu \mathrm{l}$ of $10 \%[\mathrm{w} / \mathrm{v}]$ SDS and $5 \mu \mathrm{l}$ of $10 \mathrm{mg} / \mathrm{mL}$ of proteinase $\mathrm{K}$ ) were added to tubes vortexed and incubated at $65^{\circ} \mathrm{C}$ for $10 \mathrm{~min}$. One-hundred microliters of $5 \mathrm{M} \mathrm{NaCl}$ and $N$-cetyl- $N, N, N$-trimethylammonium bromide (CTAB)-NaCl solution (4.1 $\mathrm{g}$ of $\mathrm{NaCl}$ and $10 \mathrm{~g}$ of $\mathrm{CTAB}$ per $100 \mathrm{~mL}$ ) was added and incubated at $65^{\circ} \mathrm{C}$ for $10 \mathrm{~min}$. An equal volume of chloroform: isoamyl alcohol (24:1v/v) was added to the mixture. After centrifugation for $5 \mathrm{~min}, 0.6$ volumes of isopropanol were added to the supernatant liquid to precipitate the DNA. After incubation for $20 \mathrm{~min}$ at $-20^{\circ} \mathrm{C}$ and centrifugation for $15 \mathrm{~min}$ at $12,000 \times \mathrm{g}$ and $4^{\circ} \mathrm{C}$, the pellet was washed once with $70 \%(\mathrm{v} / \mathrm{v})$ ethanol, and the air-dried pellet was dissolved in 20 $\mathrm{L} \mathrm{L}$ of Tris-EDTA buffer [17]. Purity (A260/A280) and extracted DNA concentration were then checked (NanoDrop, Thermo Scientific, Waltham, MA, USA). The DNA's truth was assessed on a $2 \%$ agarose gel stained with ethidium bromide $(0.5 \mu \mathrm{g} / \mathrm{mL})$ (Thermo Fisher Scientific, St. Leon-Rot, Germany) [18, 19].

\section{Restriction fragment length polymorphism (RFLP) analysis}

DNA fingerprinting was performed by a standardized procedure described previously (). Briefly, chromosomal DNA $(2-3.5 \mu \mathrm{g})$ was restricted with Pvull at $37^{\circ} \mathrm{C}$ overnight. The restriction fragments were separated overnight by $1 \%(\mathrm{w} / \mathrm{v})$ agarose gel electrophoresis in $1 \times$ Tris-borate-EDTA buffer. The fragments were transferred onto positively charged nylon membranes using the capillary method. RFLP analysis was performed using an internationally standardized procedure as described previously [20]. The IS 6110 fingerprint patterns were analyzed using GelCompar II software version 6.5 (Applied Maths, Sint-Martens-Latem, Belgium).

\section{Results}

Patients of the present study consisted of 6 females and 14 males who had Iranian citizenship. According to the patients' files, all sputum samples were received from the patients.

All M. tuberculosis isolates and the standard control (M. tuberculosis H37Rv strain) were examined for genomic fingerprinting and polymorphism in Alborz province. Due to technical reasons, including the quality of the genomic material extracted from the sample, DNA extracted from 20 isolates was suitable for this test. In this study, 17 isolates were enzymatically digested by Pvu II enzyme and assessed in the RFLP. Figure 1 shows the RFLP pattern of M. tuberculosis isolates using the Pvu II enzyme.

Visual comparison of high molecular weight bands (2027 to $23130 \mathrm{bp}$ ) and using Gel Pro software (analysis based on the number and size of bands), from 20 strains digested with Pvu II enzyme, after 
RFLP and hybridization with the probe IS6110 and detection, 16 different genetic types were obtained (Fig. 2), which were named HPIS1 to HPIS12 and identified, and the number of unique genotypes in this method was determined to be 16 .

The number of copies of IS6110 in each isolate ranged from 0 to 12 . However, most isolates (66\%) had copy numbers between 6 and 12. On average, each isolate had 6.9 copies of IS6110. 9 strains containing 10 to 12 copies of IS6110 5 strains containing 6 to 10 copies, and 2 strains had copies less than 6 . No copy of IS6110 was found among the 4 strains. No relationship was found between gender and copy numbers.

\section{Discussion}

The molecular epidemiology of M. tuberculosis was assessed in different parts of Iran [21-23]. Similarly, the molecular epidemiology of $M$. tuberculosis was assessed in other countries, including United States [24], Poland [25], Belgium [26], China [27], Brazil [28], Africa [29], India [30], Saudi Arabia [31], and Russia [32]. They reported some similar genetic diversity according to the applied methods and source of the infection.

The present study showed 17 different genetic types in the M. tuberculosis strains isolated from patients in Karaj, Iran, according to the RFLP-IS6110 findings. This result showed the remarkable genetic diversity of this pathogen in Alborz province, Iran. Increasing the number of isolates in future supplementary researches is likely to increase the observed polymorphism even higher than current values. The active cases of tuberculosis in this province are probably due to the infection's reactivation, and the recent transmission has a much lesser role. In the present study, a large percentage of isolates had copy numbers between 6 and 12, which the average number of copies of IS6110 marker was similar to the results of the study of Doroudchi et al. (2000) [33]. In many studies worldwide [34-36], some $M$. tuberculosis isolates did not have the IS6110 component. In the present study, 4 isolates did not have a copy of IS6110 marker. In another study in Vietnam [37], RFLP-IS6110 and Mycobacterial Interspersed Repetitive Unit Variable Number Tandem Repeat (MIRU-VNTR) techniques were used to assess the genetic characters of 2664 isolates. There was a great variety of isolates in both techniques resulting in the recurrence of latent tuberculosis infection in Vietnam. Additionally, many isolates from Vietnam did not contain any copy of the IS6110 marker, which was less resistant to antibiotics, especially streptomycin. Various researches reported that the IS6110 is the most common genetic marker for identifying and genetic identification of $M$. tuberculosis with a high resolution for DNA fingerprinting of isolated strains in the study population $[38,39]$. Therefore, this fragment can be the basis for future molecular epidemiological studies on TB. The high genetic diversity of IS6110 has been reported in previous Iranian studies [40-44]. The high genetic diversity of IS6110 in different strains of $M$.

tuberculosis probably indicates that most people with different origins have been infected. As a result, the infection's reactivation has played a more significant role in spreading tuberculosis in Iran. Although the disease's activation due to patients' infection in the years before the onset of the disease has been 
introduced as an important factor explaining this epidemiological finding, the definitive causes or reasons for this condition remain unknown.

Due to the limited number of samples studied in the present study, it is impossible to comment with certainty on mycobacteria other than the M. tuberculosis complex without the IS6110 sequence in Alborz province, Iran. So, in this case, more study is needed. Regarding the diagnosis of atypical mycobacteria in Iran, only one report was published in 2009 , which showed that 43 out of 371 samples (11.5\%) were diagnosed as non-tuberculous mycobacteria [45].

\section{Conclusion}

In conclusion, high genetic diversity was found amongst the M. tuberculosis strains isolated from patients in Alborz province, Iran, according to the IS6110-RFLP technique. A total of 17 strains were identified in RFLP. This molecular technique is acknowledged as a first-line assay in the molecular epidemiology assessment of $M$. tuberculosis. Findings revealed that $M$. tuberculosis is the leading cause of tuberculosis in the region. Given the patients' age and the genetic diversity of the strains, the assumption of hemoplasia is raised. In the end, this research can be considered as a good background for future studies in the region, comparing the obtained results with each other and better analysis of the epidemiological situation of tuberculosis in Alborz province, Iran.

\section{Declarations}

\section{Ethics approval and consent to participate}

Written informed consent was taken from volunteer patients or their parents. The relevant authorities issued ethical approval for this retrospective genotyping work at the Alborz University of Medical Sciences Ethics Committee. The present survey principles were ethically approved by the Department of Tuberculin \& Mallein, Razi Vaccine \& Serum Research Institute, Agricultural Research, Education and Extension Organization (AREEO), Karaj, Iran.

\section{Consent for publication}

Not applicable.

\section{Availability of data and materials}

All data analyzed during this study are included in this published article.

\section{Competing interests}

The authors declare that they have no competing interests.

\section{Funding}


Keyvan Tadayon received Research grants for Research at Alborz University of Medical Sciences, Karaj, Iran (grant number 97/98256). The present work was also financially supported by the Alborz University of Medical Sciences, Karaj, Iran (grant number 97/98256). Funding was specified to designation of the study, samples collection, analysis, data interpretation and writing of the manuscript.

\section{Authors' contributions}

MSF, HM and KT performed the molecular analysis, designation of primers, and drafting the manuscript. YK and NM performed the sampling and culture. HM and KT contributed in the designation of research, statistical analysis and writing of the manuscript. All authors read and approved the final manuscript.

\section{Authors' information}

${ }^{1}$ Department of Microbiology, Shahrekord Branch, Islamic Azad University, Sharekord, Iran; ${ }^{2}$ Department of Tuberculin \& Mallein, Razi Vaccine \& Serum Research Institute, Agricultural Research, Education and Extension Organization (AREEO), Karaj, Iran; ${ }^{3}$ Department of Occupational Health and Safety Engineering, Non-communicable Diseases, Research Center, Alborz University of Medical Sciences, Karaj, Iran.

\section{References}

1. World Health Organization (WHO). Global Tuberculosis report. WHO; 2020.

2. World Health Organization (WHO). Global tuberculosis control. WHO; 2011.

3. Kazerooni PA, Khazaei Z, Mousavi M, Khazaei S, Sohrabivafa M, Dehghani SL, Adineh HA, Delam H, Nejat M, Behzadi B, Esfahani MV. Prevalence of human immunodeficiency virus and tuberculosis among homeless individuals. Immunopathologia Persa. 2018;4(1):4.

4. Ahmad S, Majid Z, Mehdi M, Mubarak M. Cerebral salt wasting syndrome due to tuberculous meningitis; a case report. Journal of renal injury prevention. 2016;5(1):53.

5. Balwani MR, Kute VB, Shah PR, Wakhare P, Trivedi HL. Secondary renal amyloidosis in a patient of pulmonary tuberculosis and common variable immunodeficiency. Journal of nephropharmacology. 2015;4(2):69.

6. Makarov V, Lechartier B, Zhang M, Neres J, van der Sar AM, Raadsen SA, Hartkoorn RC, Ryabova OB, Vocat A, Decosterd LA, Widmer N. Towards a new combination therapy for tuberculosis with next generation benzothiazinones. EMBO molecular medicine. 2014 Mar;6(3):372-83.

7. Brown TS, Eldholm V, Brynildsrud O, Osnes M, Stennis N, Stimson J, Colijn C, Alexandru S, Noroc E, Ciobanu N, Crudu V. Evolution and emergence of multidrug-resistant Mycobacterium tuberculosis in Chisinau, Moldova. medRxiv. 2021 Jan 1.

8. Fox GJ, Schaaf HS, Mandalakas A, Chiappini E, Zumla A, Marais BJ. Preventing the spread of multidrug-resistant tuberculosis and protecting contacts of infectious cases. Clinical Microbiology and Infection. 2017 Mar 1;23(3):147 - 53. 
9. Makki SS, Ghorbani F, Najafizadeh K, Shafaghi S, Reza H, Vishteh K. Assessment of diagnostic value of different methods (culture, PCR and biopsy) for the diagnosis of tuberculosis in patients with bronchial anthracosis. Immunopathologia Persa. 2020 May 6;6(2):e24-.

10. Zahedi Bialvaei A, Asgharzadeh M, Aghazadeh M, Nourazarian M, Samadi Kafil H. Challenges of Tuberculosis in Iran. Jundishapur J Microbiol. 2017;10(3):e37866.

11. Almeida SM, Malaspina AC, Leite CQ, Saad MH. Usefulness of 3'-5'IS6110-RFLP genotyping and spoligotyping of Mycobacterium tuberculosis isolated in a tertiary hospital: a retrospective study detecting unsuspected epidemiological events. 61: Revista do Instituto de Medicina Tropical de São Paulo; 2019.

12. Peres RL, Vinhas SA, Ribeiro FK, Palaci M, do Prado TN, Reis-Santos B, Zandonade E, Suffys PN, Golub JE, Riley LW, Maciel EL. Risk factors associated with cluster size of Mycobacterium tuberculosis (Mtb) of different RFLP lineages in Brazil. BMC Infect Dis. 2018 Dec;18(1):1-0.

13. Ansarin K, Sahebi L, Aftabi Y, Khalili M, Seyyedi M. Comparing IS6110-RFLP, PGRS-RFLP and IS6110Mtb1/Mtb2 PCR methods for genotyping of Mycobacterium tuberculosis isolates. J Appl Microbiol. 2020 Oct;129(4):1062-70.

14. Farnad MS, Momtaz H, Mosavari N, Khosravi Y, Tadayon K. Insight into population structure of Mycobacterium tuberculosis isolates in the multiethnic province of Alborz, Iran. Iranian Journal of Microbiology. 2021 Feb 10;13(1):58-64.

15. Huard RC, de Oliveira Lazzarini LC, Butler WR, van Soolingen D, Ho JL. PCR-based method to differentiate the subspecies of the Mycobacterium tuberculosis complex on the basis of genomic deletions. J Clin Microbiol. 2003;41:1637-50.

16. McHugh TD, Gillespie SH. Nonrandom association of IS6110 and Mycobacterium tuberculosis: implications for molecular epidemiological studies. J Clin Microbiol. 1998;36:1410-3.

17. Van Soolingen D, Hermans P, De Haas P, Soll D, Van Embden J. Occurrence and stability of insertion sequences in Mycobacterium tuberculosis complex strains: evaluation of an insertion sequencedependent DNA polymorphism as a tool in the epidemiology of tuberculosis. J Clin Microbiol. 1991;29:2578-86.

18. Abdolmaleki Z, Mashak Z, Dehkordi FS. Phenotypic and genotypic characterization of antibiotic resistance in the methicillin-resistant Staphylococcus aureus strains isolated from hospital cockroaches. Antimicrobial Resistance Infection Control. 2019 Dec;8(1):1-4.

19. Ranjbar R, Farsani FY, Dehkordi FS. Phenotypic analysis of antibiotic resistance and genotypic study of the vacA, cagA, iceA, oipA and babA genotypes of the Helicobacter pylori strains isolated from raw milk. Antimicrobial Resistance Infection Control. 2018 Dec;7(1):1-4.

20. Van Soolingen D, Qian L, De Haas P, Douglas JT, Traore H, Portaels F, et al. Predominance of a single genotype of Mycobacterium tuberculosis in countries of east Asia. J Clin Microbiol. 1995;33:3234-8.

21. Ramazanzadeh R, Shakib P, Rouhi S, Mohammadi B, Mohajeri P, Borji S. Molecular epidemiology of Mycobacterium tuberculosis isolates in Iran using spoligotyping. New Microbes and New Infections. 2020 Nov 1;38:100767. 
22. Pourostadi M, Rashedi J, Poor BM, Kafil HS, Kazemi A, Asgharzadeh M. Tuberculosis control and role of molecular epidemiology studies in Iran: a systematic review. Tanaffos. 2017;16(3):190.

23. Sahebi L, Ansarin K, Hoffner S, Farajnia S, Seyyedi M, Khalili M, Monfaredan A. Molecular Epidemiology of Mycobacterium Tuberculosis Strains in the NorthWest and West of Iran. Annals of medical health sciences research. 2015;5(5):334-9.

24. Munsiff SS, Bassoff T, Nivin B, Li J, Sharma A, Bifani P, Mathema B, Driscoll J, Kreiswirth BN. Molecular epidemiology of multidrug-resistant tuberculosis, New York City, 1995-1997. Emerging infectious diseases. 2002 Nov;8(11):1230.

25. Jagielski T, Minias A, Van Ingen J, Rastogi N, Brzostek A, Żaczek A, Dziadek J. Methodological and clinical aspects of the molecular epidemiology of Mycobacterium tuberculosis and other mycobacteria. Clinical microbiology reviews. 2016 Apr 1;29(2):239 - 90.

26. Vluggen C, Soetaert K, Groenen G, Wanlin M, Spitaels M, Arrazola de Oñate W, Fauville-Dufaux M, Saegerman C, Mathys V. Molecular epidemiology of Mycobacterium tuberculosis complex in Brussels, 2010-2013. PLoS One. 2017 Feb 21;12(2):e0172554.

27. Chen L, Pang Y, Ma L, Yang H, Ru H, Yang X, Yan S, Jia M, Xu L. First insight into the molecular epidemiology of Mycobacterium tuberculosis isolates from the minority enclaves of southwestern China. BioMed research international. 2017 May 17;2017.

28. Verza M, Scheffer MC, Salvato RS, Schorner MA, Barazzetti FH, de Melo Machado H, Medeiros TF, Rovaris DB, Portugal I, Viveiros M, Perdigão J. Genomic epidemiology of Mycobacterium tuberculosis in Santa catarina, Southern Brazil. Scientific reports. 2020 Jul;30(1):1-1. 10(.

29. Chisompola NK, Streicher EM, Muchemwa CM, Warren RM, Sampson SL. Molecular epidemiology of drug resistant Mycobacterium tuberculosis in Africa: a systematic review. BMC Infect Dis. 2020 Dec;20:1-6.

30. Joseph BV, Soman S, Radhakrishnan I, Hill V, Dhanasooraj D, Kumar RA, Rastogi N, Mundayoor S. Molecular epidemiology of Mycobacterium tuberculosis isolates from Kerala, India using IS6110RFLP, spoligotyping and MIRU-VNTRs. Infection, genetics and evolution. 2013 Jun 1;16:157 - 64.

31. Al-Hajoj S, Varghese B, Al-Habobe F, Shoukri MM, Mulder A, van Soolingen D. Current trends of Mycobacterium tuberculosis molecular epidemiology in Saudi Arabia and associated demographical factors. Infection Genetics Evolution. 2013 Jun;1:16:362-8.

32. Mokrousov I. Molecular structure of Mycobacterium tuberculosis population in Russia and its interaction with neighboring countries. International journal of mycobacteriology. 2015 Mar 1;4:56 7.

33. Doroudchi M, Kremer K, Basiri EA, Kadivar MR, Van Soolingen D, Ghaderi AA. IS6110-RFLP and spoligotyping of Mycobacterium tuberculosis isolates in Iran. Scandinavian journal of infectious diseases. 2000 Jan 1;32(6):663-8.

34. Roychowdhury T, Mandal S, Bhattacharya A. Analysis of IS 6110 insertion sites provide a glimpse into genome evolution of Mycobacterium tuberculosis. Scientific reports. 2015 Jul 28;5(1):1 - 0. 
35. Howard ST, Oughton MT, Haddad A, Johnson WM. Absence of the genetic marker IS6110 from a strain of Mycobacterium tuberculosis isolated in Ontario. Canadian Journal of Infectious Diseases. 1998 Jan;9(1)(1):48-53.

36. Steensels D, Fauville-Dufaux M, Boie J, De Beenhouwer H Failure of PCR-Based IS6110 analysis to detect vertebral spondylodiscitis caused by Mycobacterium bovis. Journal of clinical microbiology. 2013 Jan 1;51(1):366-8.

37. Huyen MN, Tiemersma EW, Kremer K, de Haas P, Lan NT, Buu TN, Sola C, Cobelens FG, van Soolingen D. Characterisation of Mycobacterium tuberculosis isolates lacking IS6110 in Viet Nam. The International journal of tuberculosis and lung disease. 2013 Nov 1;17(11):1479-85.

38. Millán-Lou MI, López-Calleja Al, Colmenarejo C, Lezcano MA, Vitoria MA, del Portillo P, Otal I, Martín C, Samper S. Global study of IS6110 in a successful Mycobacterium tuberculosis strain: clues for deciphering its behavior and for its rapid detection. Journal of clinical microbiology. 2013 Nov 1;51(11):3631-7.

39. Zhou L, Ma C, Xiao T, Li M, Liu H, Zhao X, Wan K, Wang R. A new single gene differential biomarker for Mycobacterium tuberculosis complex and non-tuberculosis mycobacteria. Frontiers in microbiology. 2019 Aug 13;10:1887.

40. Asgharzadeh M, Khakpour M, Salehi TZ, Kafil HS. Use of mycobacterial interspersed repetitive unitvariable-number tandem repeat typing to study Mycobacterium tuberculosis isolates from East Azarbaijan province of Iran. Pakistan journal of biological sciences: PJBS. 2007 Nov 1;10(21):376977.

41. Rohani M, Farnia P, Nasab MN, Moniri R, Torfeh M, Amiri MM. Beijing genotype and other predominant Mycobacterium tuberculosis spoligotypes observed in Mashhad city, Iran. Indian journal of medical microbiology. 2009 Oct 1;27(4):306.

42. Azimi T, Nasiri MJ, Zamani S, Hashemi A, Goudarzi H, Fooladi AA, Feizabadi MM, Fallah F. High genetic diversity among Mycobacterium tuberculosis strains in Tehran, Iran. Journal of clinical tuberculosis and other mycobacterial diseases. 2018 May 1;11:1-6.

43. Soleimanpour S, Hamedi AsI D, Tadayon K, Farazi AA, Keshavarz R, Soleymani K, Seddighinia FS, Mosavari N. Extensive genetic diversity among clinical isolates of Mycobacterium tuberculosis in central province of Iran. Tuberculosis research and treatment. 2014 Jan 1;2014.

44. Vaziri F, KohI TA, Ghajavand H, Kamakoli MK, Merker M, Hadifar S, Khanipour S, Fateh A, Masoumi $M$, Siadat SD, Niemann S. Genetic diversity of multi-and extensively drug-resistant Mycobacterium tuberculosis Isolates in the capital of Iran, revealed by whole-genome sequencing. Journal of clinical microbiology. 2019 Jan 1;57(1).

45. Heidari F, Farnia P, Noroozi J, Majd A, Tajedin E, Masjedi MR, Velayati A. The rapid identification of atypical mycobacterium in pulmonary tuberculosis (ptb) patients: evaluation of qub3232 locus using the vntr method. J Adv Med Biomed Res. 2009;17(67):33-44.

\section{Figures}




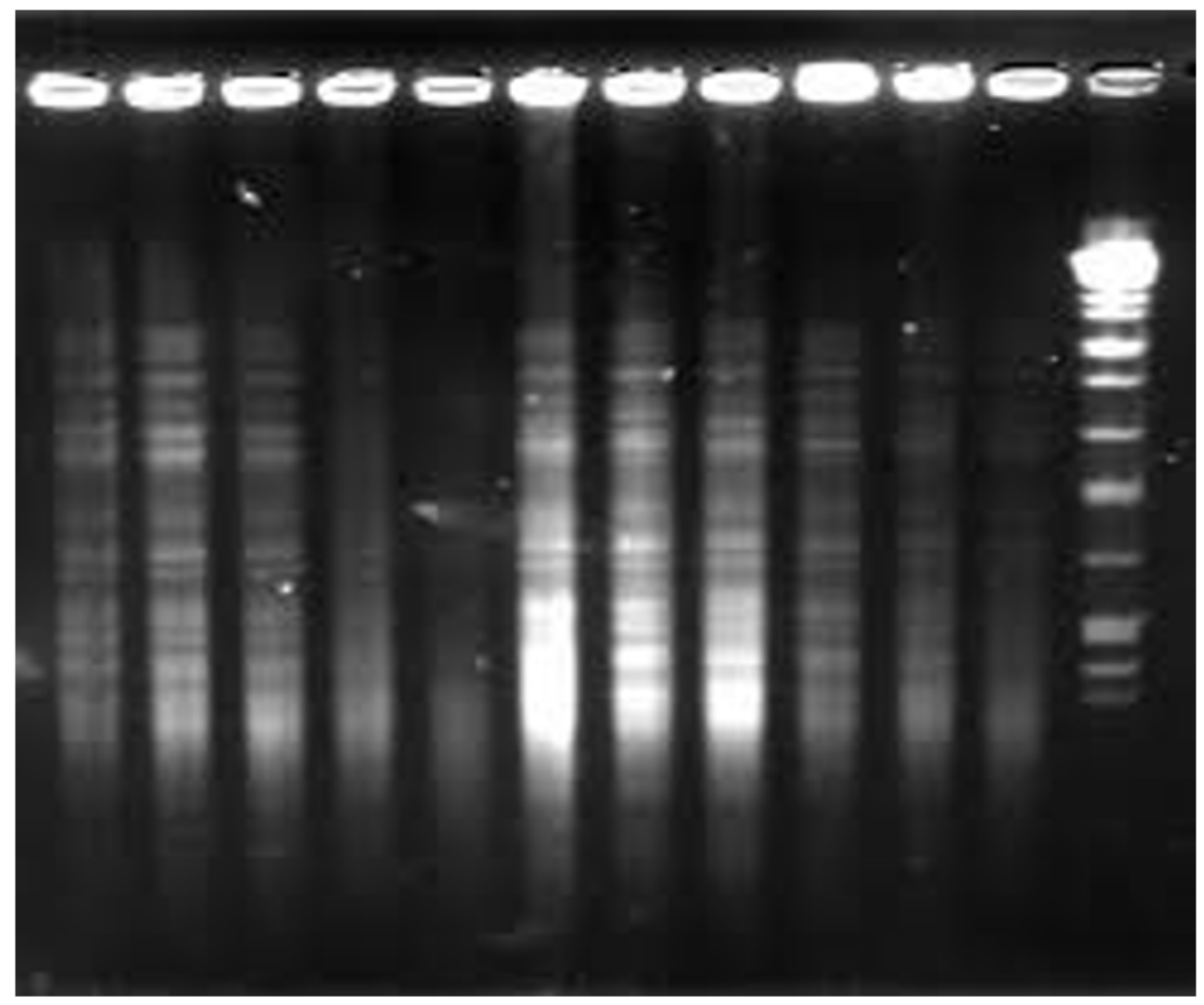

Figure 1

RFLP pattern of M. tuberculosis isolates using the Pvu II enzyme. 


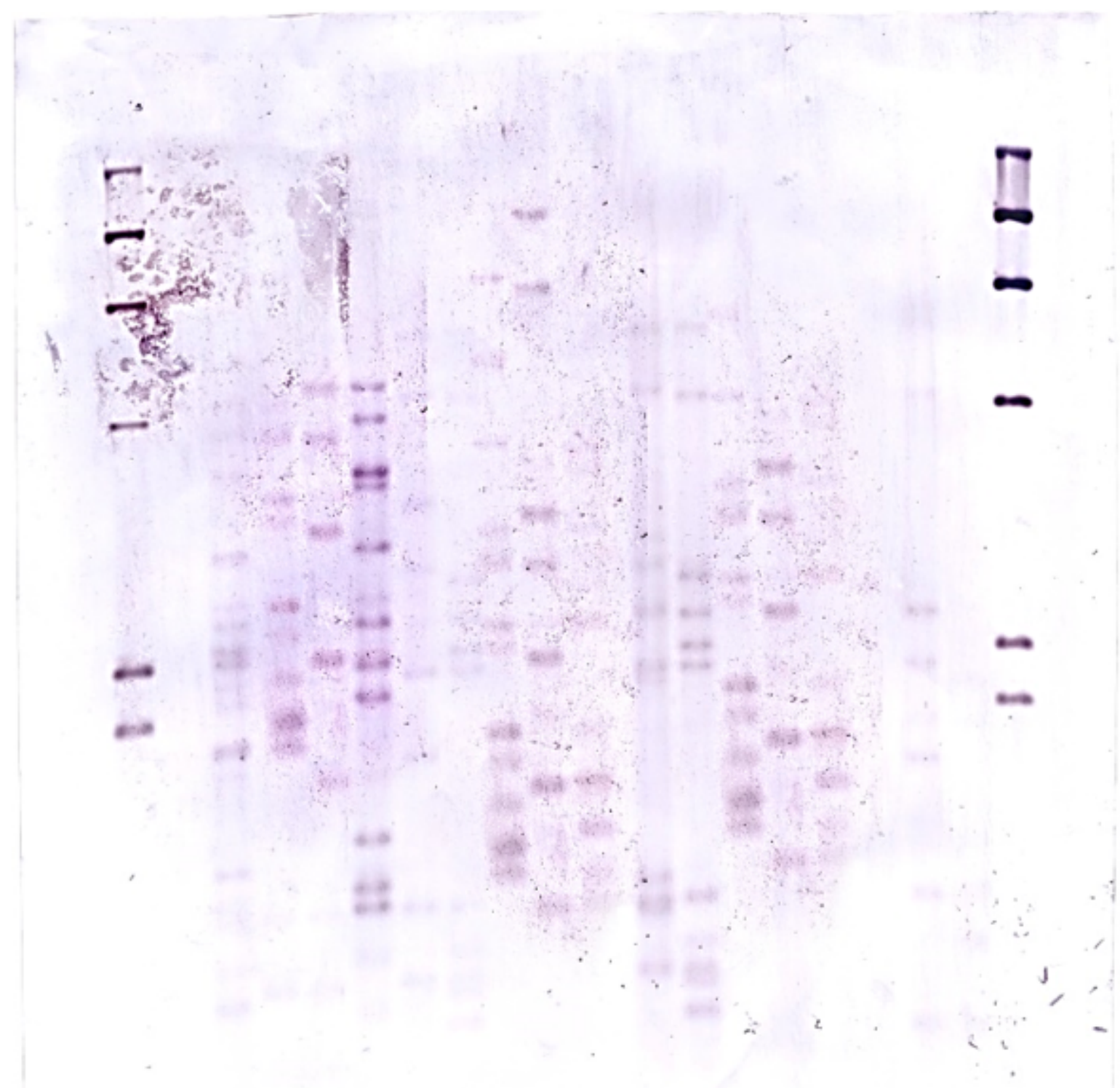

Figure 2

Findings of the RFLP test based on IS6110 markers and Pvu II enzyme. 